\title{
Upper GI Hemorrhage from Duodenal Ulcer due to Post- Cholecystectomy Clip Migration
}

\author{
MM HUSSAIN $^{\mathrm{a}}$, MAH BHUIYA ${ }^{\mathrm{b}}, \mathrm{F} \mathrm{AHMED}^{\mathrm{c}}$, MA MASUD $^{\mathrm{d}}$, A RAHMAN $^{\mathrm{e}}$, \\ M RAHMAN $^{\mathrm{f}}, \mathrm{AKAFI}^{\mathrm{g}}, \mathrm{M}^{\mathrm{RAHMAN}}{ }^{\mathrm{h}}$
}

\begin{abstract}
Summary:
Post Cholecystectomy Clip Migration (PCCM) is rare but a recognized complication following Laparoscopic Cholecystectomy. Majority are related to stone formation in CBD. Only a few case reports has been made so far where metallic clips were found to cause duodenal ulcer. We report a case who presented with upper GI bleeding weeks after Laparoscopic Cholecystectomy. Endoscopic removal was
\end{abstract}

\section{Introduction:}

Gall stone disease is a common surgical problem. Following introduction of Laparoscopic Cholecystectomy ( LC ), this has been the gold standard surgical procedure for gall bladder stones. Metallic clips are used in most cases for occlusion of cystic duct and cystic artery. Complications of up to around $5 \%$ cases are seen in these patients ${ }^{1}$. Immediate complications related to LC are bile duct injury, major bile leakage, wound infection; and late complications includes obstructive jaundice and Post Cholecystectomy Clip Migration (PCCM) ${ }^{2}$. Clip migration is a unique complication related to $\mathrm{LC}$. Metallic (Titanium) clips used for cystic duct and cystic artery occlusion gets dislodged and penetrate into common bile duct and acts as a nidus for stone formation. Walker ${ }^{3}$ in 1978 first reported a case where metallic clip was found to erode into CBD forming a stone around it following open cholecystectomy. Raoul and co-workers in 1992 reported a patient of duodenal

a. Prof. M Margub Hussain, Professor of Surgery, Dhaka Medical College and Hospital.

b. Prof. MA Hashem Bhuiya, Professor of Surgery.

c. Prof. Faruque Ahmed, Professor of Gastroenterology.

d. Prof. MA Masud, Professor of Gastroenterology.

e. Dr. Atiar Rahman, Assistant Professor, Surgery.

f. Dr. Mahfuzur Rahman, Assistant Registrar, Surgery.

g. Dr. Abdulla-hel Kafi, Medical Officer, Gastroenterology.

h. Dr. Mizanur Rahman, Assistant Registrar, Surgery.

Address for Correspondence: Prof. M Margub Hussain, Professor of Surgery, Dhaka Medical College and Hospital.

Received: 13 October, 2011

Accepted: 13 September, 2012 attempted first. As all the clips could not be removed and patient continued to have problems, distal partial gastrectomy extending up to proximal duodenum and removal of all the clips were required for complete relief.

Key Words: Laparoscopic Cholecystectomy, Clip Migration, Haematemesis, Duodenal Ulcer.

(J Bangladesh Coll Phys Surg 2012; 30: 225-228)

ulcer where two endoclips used for laparoscopic cholecystectomy were found at the base of ulcer ${ }^{4}$. A few other reports of duodenal ulcer and heamatemesis were also made by Reis $\mathrm{LD}^{5}$, Yao ${ }^{6}$, Wasserberg ${ }^{7}$, Samim $^{8}$. Buczaki and his colleagues reported a case of clip migration after tubal ligation into free peritoneal cavity and ultimately presenting as a cause of persistent peri-anal fistula ${ }^{9}$. Migrated endoclip was found within a subphrenic abscess three years following $\mathrm{LC}^{10}$. Clip migration has also been reported following different other surgical procedures like breast biopsy, neurosurgical procedures, hepatic lobectomy tubal ligation and urological procedure. ${ }^{11-17}$

This communication is a report of a case who had LC for gall stones and then developed duodenal ulcer due to migration of clips and presented as recurrent haematemesis and malaena with epigastric pain. This patient eventually required surgery.

\section{Case Report:}

Mr. AH, 25 year old male was admitted in March 2010 with history of repeated episodes right upper quadrant abdominal pain, fever and vomiting for about two years. He did not have jaundice before. Endoscopic examination reported distal gastritis, but no ulcer was seen. USG of hepetobiliary system revealed multiple stones in a thick walled gall bladder. Surgery (LC) was done on 9th March, 2010. At operation gall bladder was found contracted, thick walled and adherent to adjacent duodenum and hepatic flexure of colon. Adhesions were divided after careful dissection avoiding injuries to the organs. Multiple clips were used for division of thick 
dilated cystic duct and to control bleeding around the duct. Post operatively the patient recovered as expected and was released on $3^{\text {rd }}$ post operative day.

Six months after initial operation, the patient was admitted after three episodes of severe vomiting of blood and passage of black tarry stool along with epigastric pain. Endoscopy showed an ulcer in the duodenum. The floor was covered with clots. Local adrenalin injection was given. He was treated conservatively and had blood transfusion along with anti ulcerant drugs.

Two weeks later the patient had malaena again and was readmitted. Upper GI endoscopy revealed previous duodenal ulcer did not heal as expected. Three metallic Clips were found impacted at the base of ulcer. Two clips were removed through endoscope and local injection of adrenaline was given to control bleeding. But bleeding continued and the patient was transferred for surgical intervention. Partial gastrectomy extending up to ulcer bearing area of duodenum was excised. Two other clips were removed during operation and bleeding was controlled by sutures. Post operatively patient recovered completely without any other complication ( Fig 1 ).

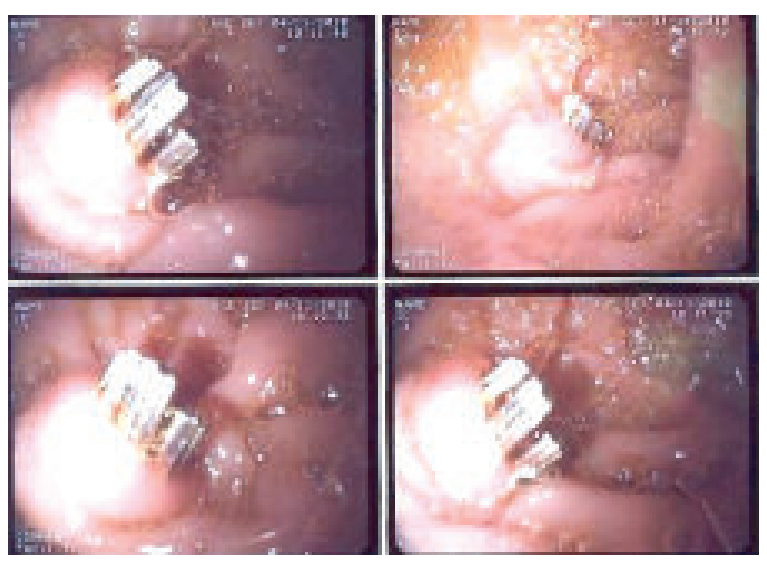

Fig.-1: Showing three clips (endoscopic view) in first part of duodenum

\section{Discussion:}

Formation of stone around a silk suture was first documented in 1897 by Homans ${ }^{18}$. Thereafter, reports were made of CBD stones formed around materials used per operatively like non absorbable sutures, fragments of $\mathrm{T}$ - tube, gauze; foreign bodies penetrating during injury and alimentary materials like fibers, seeds and skin of fruits or vegetables, eggs and fragments of bodies of intestinal parasites and ingested foreign bodies ${ }^{19}$. Reports of stone formation around migrated endoclips followed introduction and popular use of Laparoscopic procedures.

Complications following $\mathrm{LC}$ approaches to $5.5 \%$ which is more than complications following open operation. Unique to LC is clip migration. Metallic endoclips are used during the procedure for cystic duct and cystic artery occlusion and also for control of bleeding during the procedure. Though ligatures ( extra corporeal or intra corporeal ) and endoloops, Hemoclips, ultrasonic devices are also used for this purpose. Titanium clips are used in vast majority cases because of ease of application and low cost appliances. But these clips can slip from the position and lie freely in peritoneal cavity and erode into nearby hollow viscus.

First report of such clip migration following a Laparoscopic Cholecystectomy was made by Raoul and his colleagues ${ }^{4}$. The patient presented with cholangitis. Metallic clip used for cystic duct was removed by sphincterotomy. There are reports of obstructive jaundice, pancreatitis, Sub-phrenic abscess, duodenal ulceration following $\mathrm{LC}^{10}$. Wang ${ }^{20}$ recorded a case of clip dislodged from cystic duct into the $\mathrm{T}$ tube tract following Laparoscopic choledochotomy.

Chong 2 in a review of 69 reported cases investigated the problem of clip migration. Time from primary operation to clinical presentation of displacement of endoclips ranged from 11 days to 20 years. Most displacements occur in about 2 years. Later the frequency gradually reduces. Most common presentation were abdominal pain, fever and jaundice and diagnosed as obstructive jaundice (37.7 \%). In others diagnosis was Cholangitis $(27 \%)$, biliary colic $(18.8 \%)$ and acute pancreatitis $(8.7 \%)$.

Non- biliary complications of clip migration are rare, about $4 \%$ of all complication ( 10 ) and include erosion into first part of duodenum causing an ulcer. Such a case was first reported in 2000 by Reis 5 . Following this, there were only a few reports of duodenal ulcer due to a migrated clip. Yao $\mathrm{C} \mathrm{C}^{6}$ reported a case in which there was bile leakage following slippage of cystic duct stump one day after LC. A biloma formed and was managed by a biliary stent. The slipped clip later eroded through 
first part of duodenum. Samim $\mathrm{MM}^{8}$ reported a case of duodenal ulcer 15 years after LC in a patient of 75 years. This patient had gastric outlet obstruction due to an ulcer containing a clip at the base diagnosed by endoscopy. At operation a large ulcer was excised with removal of clip. Wasserberg ${ }^{7}$ reported two cases in 2003. Both the patients presented with acute upper G I bleeding and was managed by endoscopic removal of the clips. In our case patient had multiple episodes of upper G I haemorrhage. Diagnosis was made by endoscopy. Endoscopic removal of all clips was not possible as two of them were firmly attached. Surgery had to be performed as patient continued to have pain and bleeding. At operation clips along with ulcer bearing area of duodenum was excised. Bleeding vessels were sutured.

The exact mechanism of clip displacement could not be identified. One or more factors that may contribute to clip migration are short cystic duct stump, inappropriate application of clips specially in thick walled unyielding duct, cystic duct ischemic necrosis, suppurative complication of stump ${ }^{21}$. Number of clips used during the procedure is also regarded as an important factor for clip displacement. The use of four or more clips, manipulation after clipping has been associated with more frequent clip migration. Surgery during acute inflammatory process i.e. acute cholecystitis and also chronic inflammation and dense adhesion increases the chances of clip migration. Double stapling for thick cystic duct with one clip on top of another is also believed to be an unsafe technique. One hypothesis is that a biloma forms due to bile leakage through cystic duct due to improper clipping. This eventually produces local necrosis of cystic duct stump and the free clip enters the CBD. It may pass without or minimum clinical symptom or may form a nidus for a CBD stone. Others believe that clips erode the bile duct and cause local inflammatory process ${ }^{22}$.

To avoid the problem of clip migration and also to avoid complications of bile leakage it is always recommended that great care be taken to ensure secure occlusion of the cystic duct by proper application of clips. Meticulous dissection of Calot's triangle, removal of wandering clips and loosely applied clips has been advised ${ }^{7}$. This is more important in cases of dense adhesions and thick dilated cystic duct. Double stapling with one clip on top of another is unsafe and must always be avoided. Unnecessary manipulation like repeated suction may displace the clip. The more recently developed clips (for instance, those with serrations or grooves), which are claimed to hold more tightly with less chance of slippage, would be advantageous in this regard. Allan ${ }^{23}$ has suggested use of absorbable clips during cholecystectomy and Westervelt ${ }^{24}$ ultrasonic device or harmonic scalpel for duct and bleeding vessels.

Endoscopic removal is possible in majority cases and should always be tried. Surgery is recommended when there is complications like bleeding or if endoscopic removal is not successful ${ }^{22}$. In presenting patient pain and bleeding continued even after removal of two clips by endoscopic procedures and hence surgery became inevitable.

\section{Conclusion:}

Newer complications of laparoscopic cholecystectomy and other surgical procedures using surgical clips must be kept in mind during post operative monitoring and management. Secured application of clips is very important. Techniques to avoid complication should be applied while performing procedures involving clip application.

\section{Acknowledgement:}

We are indebted to Professor Vui Hang Chong and Professor Chee Fui Chong of Raja Isteri Pengiran Anak Saleha ( RIPAS ) Hospital, Bandar Seri Begawan, Brunei Darussalam for mailing a copy of their article on request.

\section{Reference:}

1. Buanes T, Mjaland O. Complications in laparoscopic and open Cholecystectomy : a prospective comparative trial. Surg. Laparosc Endosc. 996; 6: 266-272.

2. Chong $\mathrm{V} \mathrm{H}$, Chong $\mathrm{C}$ F. Biliary complications secondary to post Cholecystectomy clip migration: A review of 69 cases. J Gastrointest Surg ; 2010; 14 : 688-696.

3. Walker WE, Avant GR, Reynolds VH. Cholangitis with a silver lining. Arch Surg; 1979; 114: 214- 215

4. Raoul JL, Bretagne JF, Siproudhis L, Heresbach D, Campion JP, Gosselin M. Cystic duct clip migration into the common bile duct: a complication of laparoscopic cholecystectomy treated by endoscopic biliary sphincterotomy. Gastrointest Endosc; 1992; 38: 608-611

5. Reis LD. Surgical Clips incorporated into a duodenal ulcer: a rare complication after elective laparoscopic cholecystectomy. Endoscopy, 2000; 32 : S3 
6. Yao CC, Wong HH, Chen CC, Wang CC, Yang CC, Lin CS. Migration of endoclip into duodenum. A rare complication after laparoscopic cholecystectomy Surg Endosc. 2001; 15(2):217.

7. Wasserberg N, Gal E, Fuko Z, Niv Y, Lelcuk S, Rubin M. Surgical clip found in duodenal ulcer after laparoscopic cholecystectomy. Surg Laparosc Endosc Percutan Tech. $2003 ; 13(6): 387-8$.

8. Samim M M,. Armstrong C P. Surgical clip found at duodenal ulcer after laparoscopic cholecystectomy: Report of a case. Int. Jour. Surg 2001; 6: 473-474

9. Buczacki S J. Keeling N, Krishnasamy T. Migration of a Tubal Ligation Clip Causing Chronic Perianal Sinus: An Unrecognized Complication of Floating Clips Journal of Pelvic Medicine \& Surgery: 2007; 13(4): 217-218

10. Stewart JAD, Gunn MC, Rathbone BJ, Robertson GSM. Shortness of breath and Jaundice Postgrad Med J. 1997; 73(865); 759-760.

11. Kass R, Kumar G, Klimberg V S, Lawrence Kass L, Tillman R H. Johnson A, Colvert M, Lane S, Harshfield D, Korourian S, Parrish R P, Mancino A. Clip migration in stereotactic biopsy; The American Journal of Surgery 2002; 184(4): 325-331

12. Yasui K, Kotani Y, Takeda Y et al. Migration of intracranial hemostatic clip into the lumbar spinal canal causing sacral radiculopathy: a case report. Spine 2003; 28(24): 511-514.

13. Chen C C, Zinn P O, Kasper E M and Ogilvy C S. Craniospinal migration of a metallic clip placed during arteriovenous malformation resection - A case report, review of the literature, and management strategies BMC 2010.

14. Alsulaiman R, Barkun J, Barkun A. Surgical clip migration into the common bile duct after orthotopic liver transplantation. Gastrointestinal Endoscopy 2006; 64 (5): 833-834.

15. Kesby GJ, Korda AR. Migration of a Filshie clip into the urinary bladder seven years after laparoscopic sterilisation. Br J Obstet Gynaecol. 1997; 104(3): 379-382.

16. Denton GW, Schofield JB, Gallagher P. Uncommon complications of laparoscopic sterilisation. Ann R Coll Surg Engl. 1990;72(3):210-211.

17. Lin CT, Kao CH, Lin CM, Cha TL, Sun GH, Wu ST. Clip Migration in Urethral Stump after Radical Cystectomy. J Med Sci, 2011, 31(1): 041-042

18. Homans J. Silk suture within gallbladder stones. Ann Surg 1897; 26: 114-116

19. Ban JL, Hirose FM, Benfield JR. Foreign bodies of the biliary tract: report of two patients and a review of the literature. Ann Surg 1972; 176: 102-107.

20. Wang YL, Zhang GY, Wang L, Hu SY. Metallic clip migration to T-tube sinus tract after laparoscopic choledochotomy. Acta Chirurgica Belgica 2009; 109(2):242-4.

21. Cetta F, Lombardo F, Baldi C, Cariati A. Clip migration within the common duct after laparoscopic cholecystectomy: a case of transient acute pancreatitis in the absence of associated stones. Endoscopy 1997; 29: S59-S60.

22. Dolay K, Alis H, Soylu A, Altaca G, Aygun E. World J Gastroenterol; 2007; 13 (47 ) 6446-6448

23. Allan A, Cooper MJ, Leaper DJ. A new absorbable ligating clip for use in cholecystectomy. J R Coll Surg Edinb 1984; 29: 53-54.

24. Westervelt J. Clipless cholecystectomy: broadening the role of the harmonic scalpel. JSLS 2004; 8: 283-285. 